
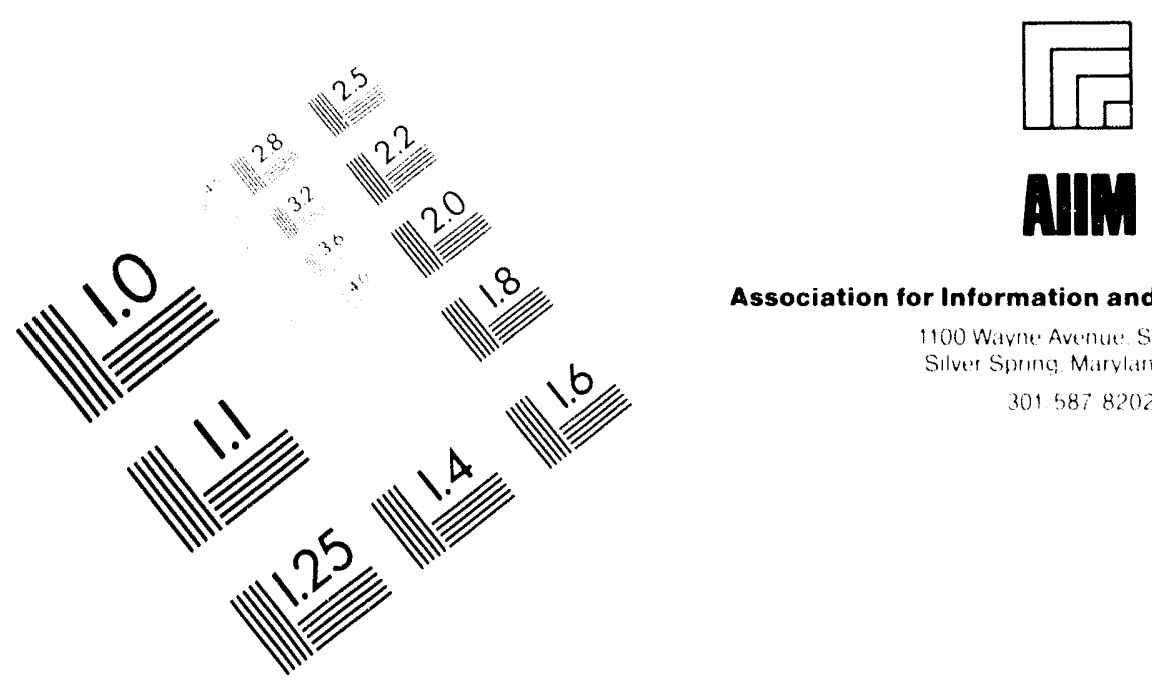

Association for Information and Image Management

1100 Wayne Avernus Sutte 1100

Silve:s Somng Maryland ? 04910

301.5878202

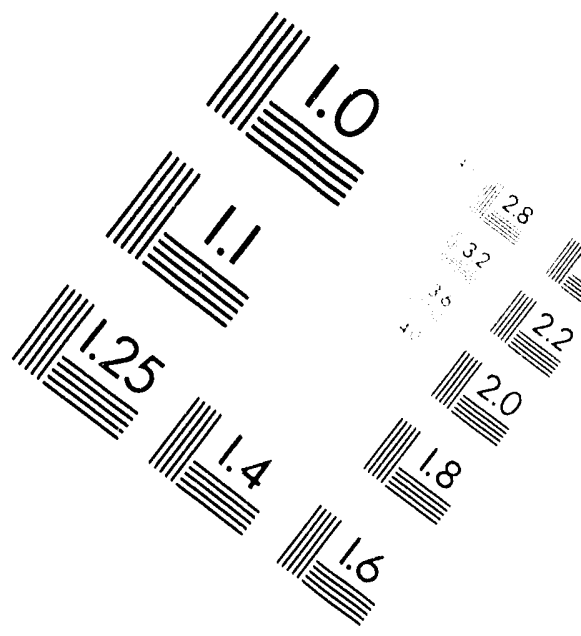

Centimeter

|m

Inches
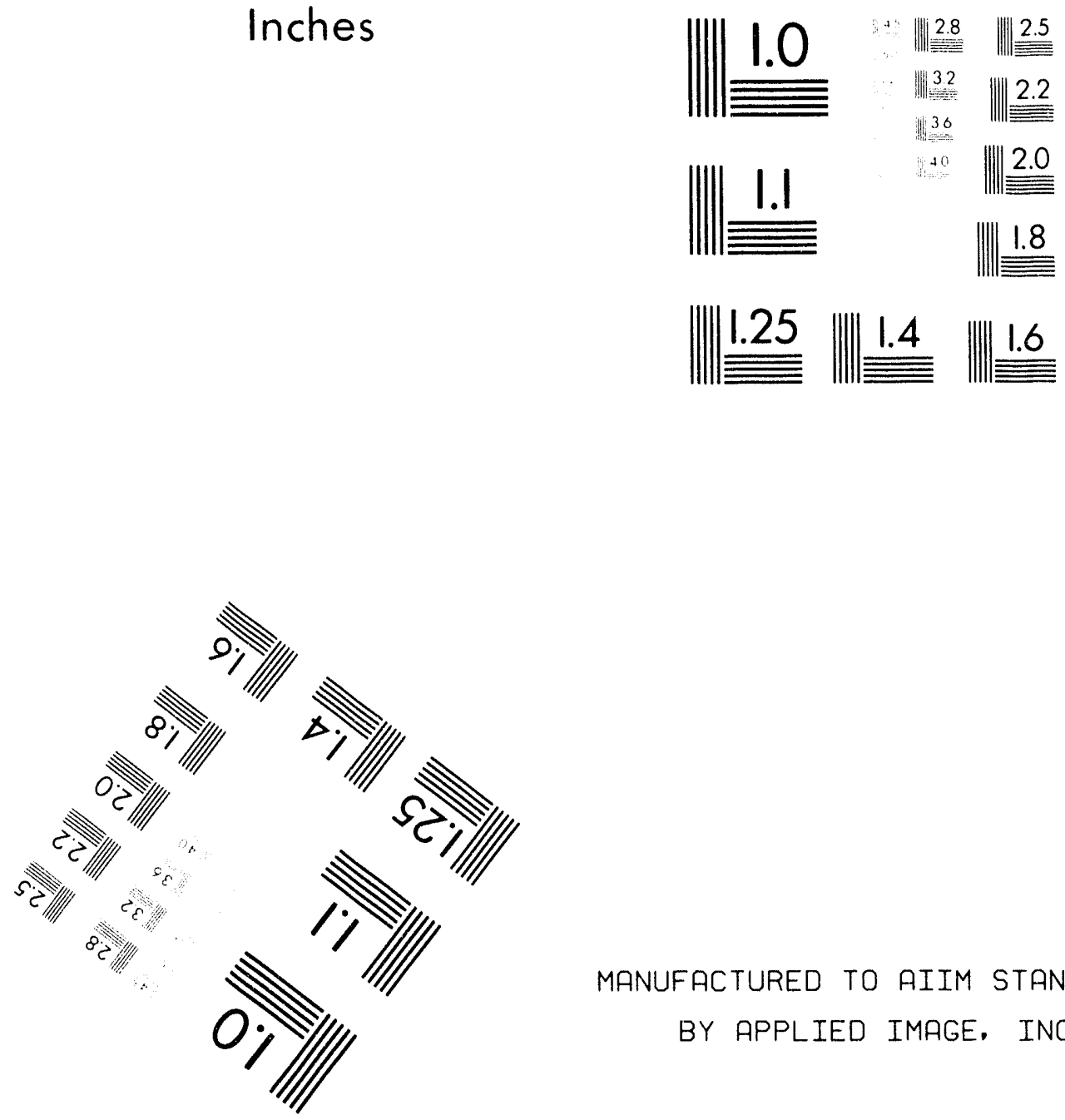

MANUFACTURED TO AIIM STANDARDS

BY APPLIED IMAGE, INC.

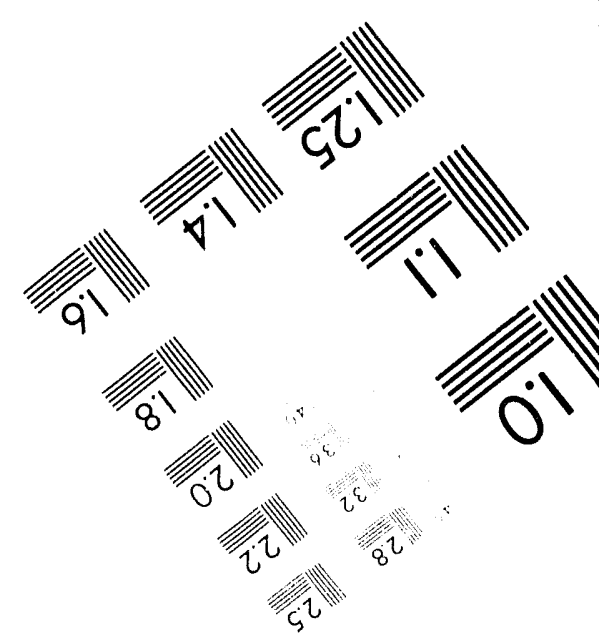



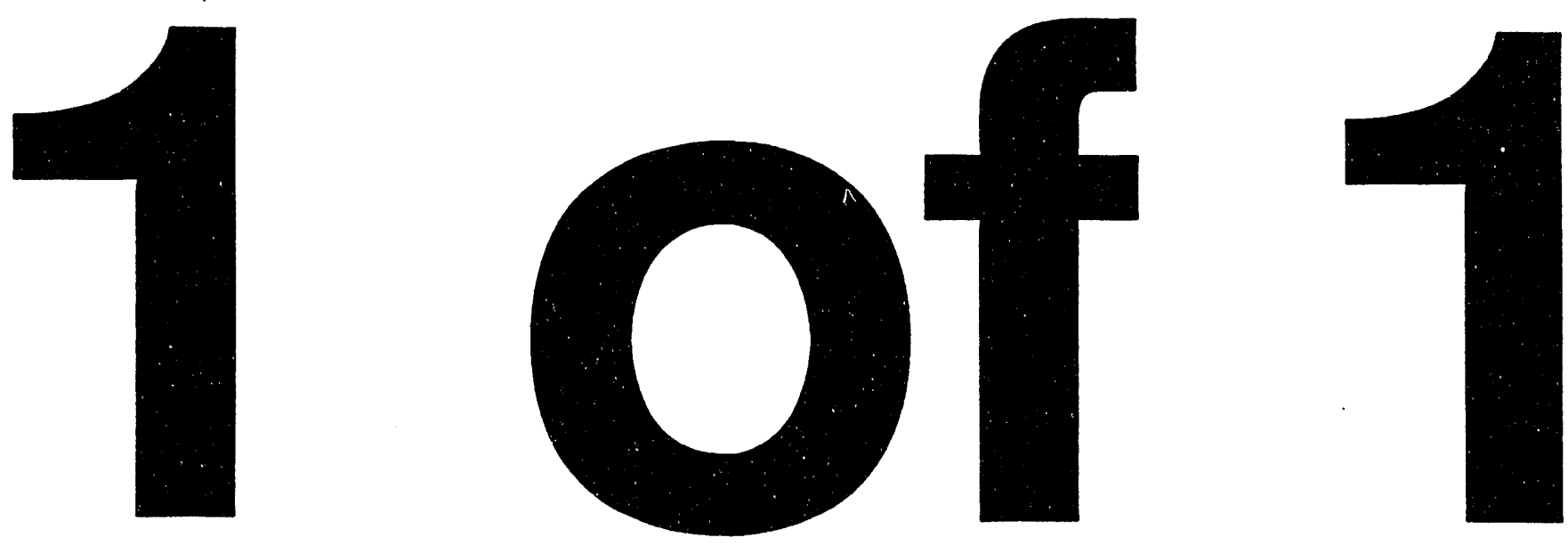


\title{
Corf-940552--7
}

UCRL-JC-116270

PREPRINT

\section{Design of the Divertor Thomson Scattering System on DIII-D}

\author{
T. N. Carlstrom \\ General Atomics \\ San Diego, CA
}

J. H. Foote, D. G. Nilson, and B. W. Rice Lawrence Livermore National Laboratory Livermore, $\mathrm{CA}$

This paper was prepared for

10th Topical Conference on

High Temperature Plasma Diagnostics

Rochester, NY

May 8-12, 1994

May 1994

This is a preprint of a paper intended for publication in a journal or proceedings. Since changes may be made before publication, this preprint is made available with the understanding that it will not be cited or reproduced without the permission of the author. 


\section{DISCLAIMER}

This document was prepared as an account of work sponsored by an agency of the United States Government. Neither the United States Government nor the University of California nor any of their employees, makes any warranty, express or implied, or assumes any legal liability or responsibility for the accuracy, completeness, or usefulness of any information, apparatus, product, or process disclosed, or represents that its use would not infringe privately owned rights. Reference herein to any specific commercial products, process, or service by trade name, trademark, manufacturer, or otherwise, does not necessarily constitute or imply its endorsement, recommendation, or favoring by the United States Government or the University of California. The views and opinions of authors expressed herein do not necessarily state or reflect those of the United States Government or the University of California, and shall not be used for advertising or product endorsement purpose. 


\title{
Design of the Divertor Thomson Scattering System on DIII-D*
}

\author{
T.N. Carlstrom, ${ }^{a}$ ) J.H. Foote, D.G. Nilson, and B.W. Rice \\ Lawrence Livermore National Laboratory, Livermore, California
}

Local measurements of $n_{e}$ and $T_{e}$ in the divertor region are necessary for a more complete understanding of divertor physics. We have designed an extension to the existing multipulse Thomson scattering system ${ }^{1}$ to measure $n_{e}$ in the range $5 \times 10^{18}$ to $5 \times 10^{20} \mathrm{~m}^{-3}$, and $T_{e}, 5-500 \mathrm{eV}$, with $1 \mathrm{~cm}$ resolution from $1-21 \mathrm{~cm}$ above the floor of the DIII-D vessel (8 spatial channels), in the region of the $\mathrm{X}$-point for lower single-null diverted plasmas. One of the existing 8 , $20 \mathrm{~Hz}, \mathrm{Nd}$ :YAG lasers will be redirected to a separate vertical port, and viewed radially with a specially designed f/6.8 lens. Fiber optics carry the light to additional polychromators whose interference filters have been optimized for low $T_{e}$ measurements. Other aspect of the system, including the beam path to the vessel, polychromator

\footnotetext{
a) General Atomics, San Diego, California 92186-9784.
} 
design, real time data acquisition, laser control, calibration facility, and DIII-D timing and data acquisition interface will be shared with the existing multipulse Thomson system. An in-situ laser alignment monitor will provide alignment information for each laser pulse. 


\section{INTRODUCTION}

The divertor heat flux and particle exhaust are critical issues in the design of ITER. The physics understanding associated with these issues is receiving increased attention through the advanced divertor program on the DIII-D tokamak. Contributing to this effort, measurements of basic plasma parameters such as density and electron temperature in the divertor are necessary for a more complete understanding of divertor physics. Although the plasma edge is fairly well diagnosed in the main body of the DIII-D plasma through Thomson scattering and other diagnostics, there are no $n_{e}$ or $T_{e}$ measurements made in the divertor except for Langmuir probes on the divertor floor. Discrepancies between the total power inferred from Langmuir probe measurements and infrared camera measurements indicate that we may not have a complete understanding of the sheath physics near the divertor floor. Measurements of $n_{e}$ and $T_{e}$ along the separatrix between the divertor floor and the X-point are useful for understanding the physics of the divertor operation and for testing and benchmarking simulation codes such as LEDGE and DEGAS. 
The multipulse Thomson scattering diagnostic on DIII- $\mathrm{D}^{1}$ has demonstrated its capabilities for reliable and accurate $n_{e}$ and $T_{e}$ profiles, including scrape-off-layer measurements down to $10 \mathrm{eV}$. It consists of $8,20 \mathrm{~Hz}$, Nd:YAG lasers, 40 spatial channels, and a real-time data acquisition and computer control system. We are extending this system by adding another collection lens and redirecting one of the existing lasers beams to the divertor region.

\section{EXPERIMENTAL ARRANGEMENT}

In order to utilize as much of the existing hardware as possible, the laser beam is introduced into the divertor region through a vertical port at the same toroidal location as the present system. This allows the beam line and tower structure, which holds the final laser steering mirrors, focussing lens and the collection lens, to be used by both systems. A cross-section of the machine is shown in Fig. 1. To reduce stray laser light, baffles have been designed which collimate scattered light from the input and exit windows into the opposite port. A 
beam dump, energy monitor, and alignment camera are mounted just outside the laser exit window.

Because access to the open divertor of DIII-D is limited by the presence of a bias divertor ring, a cyropump, and a large baffle plate surrounding the cyropump, the collection optics could not be placed at the closest port but is placed just above the interfering hardware as shown in Fig. 2. The f/6.8 collection lens has a magnification of 0.29 and is made with two elements with a mirror between them so the first aspheric surface can be as close to the scattering volume as possible. The laser beam from 1-21 $\mathrm{cm}$ above the divertor floor is imaged on an array of $8,1.5 \mathrm{~mm} \times 3.0 \mathrm{~mm}$ fiber bundles. The projected area of the fiber at the scattering volume is about $5 \mathrm{~mm} \mathrm{x}$ $10 \mathrm{~mm}$, which allows some misalignment tolerance of the $3.5 \mathrm{~mm}$ diameter laser beam. The spatial locations can be selected from an array of fiber mounting locations, with a resolution of about $15 \mathrm{~mm}$. A guard window, vacuum window, and shutter are mounted on a re-entrant port as shown in Fig. 3. 


\section{DETECTION SYSTEM}

The detection system uses the same polychromators ${ }^{2}$, silicon avalanche photodiodes ${ }^{3}$, and data acquisition ${ }^{4}$ as the existing Thomson system except that the interference filters in the polychromators have been optimized for low temperature. The expected range of $n_{e}$ and $T_{e}$ values in the divertor are estimated from previous Langmuir probe measurements, edge Thomson scattering, and computer simulations to be in the range of $5 \times 10^{18}$ to $5 \times 10^{20} \mathrm{~m}^{-3}$, and $5-500 \mathrm{eV}$. Eight polychromators ( 4 existing and 4 additional) will have interference filters optimized for this range.

Using the filter transmissions shown in Fig. 4, the relative error in $n_{e}$ and $T_{e}$ has been calculated using a simulation code which includes the effect of excess noise of the detectors due to the avalanche process, electronic noise of the amplifiers, background light estimated from data taken with the present Thomson system, and various geometrical aspects of the system. Figure 5 shows the calculated relative error as a function of temperature for a density of $5 \times 10^{19} \mathrm{~m}^{-3}$. 
Errors less than $10 \%$ are achieved for $T_{e}$ down to $5 \mathrm{eV}$ with measurements possible to about $2 \mathrm{eV}$. The critical aspect of the polychromator that permits this low temperature capability is the narrow bandwidth $(2.0 \mathrm{~nm})$ interference filter closest to the laser line (central wavelength $1062.0 \mathrm{~nm})$. This filter is placed last in the polychromator cascade and a modified mount is used so that incident light can strike it normally instead of at 4 degrees. Rejection of the laser line at $1064.3 \mathrm{~nm}$ is expected to be $10^{-5}$.

Detector electronics provide a pulsed channel output where the background light has been subtracted with a delayline technique. This allows full range of the 11 bit gated integrator to be utilized for the Thomson scattered signal. A DC coupled channel provides background light signals so that error bars can be estimated accurately. The DC channel also permits calibration using standard DC light sources. 


\section{CALIBRATION AND ALIGNMENT}

In order to measure low temperatures, an accurate wavelength calibration is necessary. We use a computer controlled monochromator with $0.1 \mathrm{~nm}$ resolution. A precise calibration of the monochromator at the laser wavelength is obtained by illuminating the input slit with a portion of the laser output. Relative channel to channel gain is obtained using a calibrated photodiode traceable to NBS standards (EGG model 640). Absolute gain is calibrated using Rayleigh scattering in argon.

Because of access difficulties, a laser beam alignment target which enters the vacuum will be omitted and we will rely instead on a careful initial alignment of the collection lens and fibers when the machine is vented and on in-situ alignment monitors which indicate the transverse alignment of each laser pulse. ${ }^{5}$ Feedback alignment of the laser beam along the beam line is provided by cameras. 


\section{ACKNOWLEDMENT}

We wish to thank D. Aikens for help with the lens design and C.M. Greenfield for help with the polychromator simulation code. We also acknowledge useful discussions with C.L. Hsieh. *This work is supported by the U.S. Department of Energy by Lawrence Livermore National Laboratory under Contract W-7405-ENG-48, and by General Atomics, DE-AC03-89ER51114.

\section{REFERENCES}

1 T.N. Carlstrom, G.L. Campbell, J.C. DeBoo, R. Evanko, J. Evans, C.M. Greenfield, J. Haskovec, C.L. Hsieh, E. McKee, R.T. Snider, R.E. Stockdale, P.K. Trost, and M.P. Thomas, Rev. Sci. Instrum. 63, 4901 (1992).

2 T.N. Carlstrom, J.C. DeBoo, R. Evanko, C.M. Greenfield, C.L. Hsieh, R.T. Snider, and P.K. Trost, Rev. Sci. Instrum. 61, 2858 (1990). 
${ }^{3}$ C.L. Hsieh, J. Haskovec, T.N. Carlstrom, J.C. DeBoo, C.M. Greenfield, R.T. Snider, and P.K. Trost, Rev. Sci. Instrum. 61, 2855 (1990).

${ }^{4}$ C.M. Greenfield, G.L. Campbell, T.N. Carlstrom, J.C. DeBoo, C.L. Hsieh, R.T. Snider, and P.K. Trost, Rev. Sci. Instrum. 61, $3286(1990)$.

5 P.K. Trost, T.N. Carlstrom, J.C. DeBoo, C.M. Greenfield, C.L. Hsieh, and R.T. Snider, Rev. Sci. Instrum. 61, 2864 (1990). 


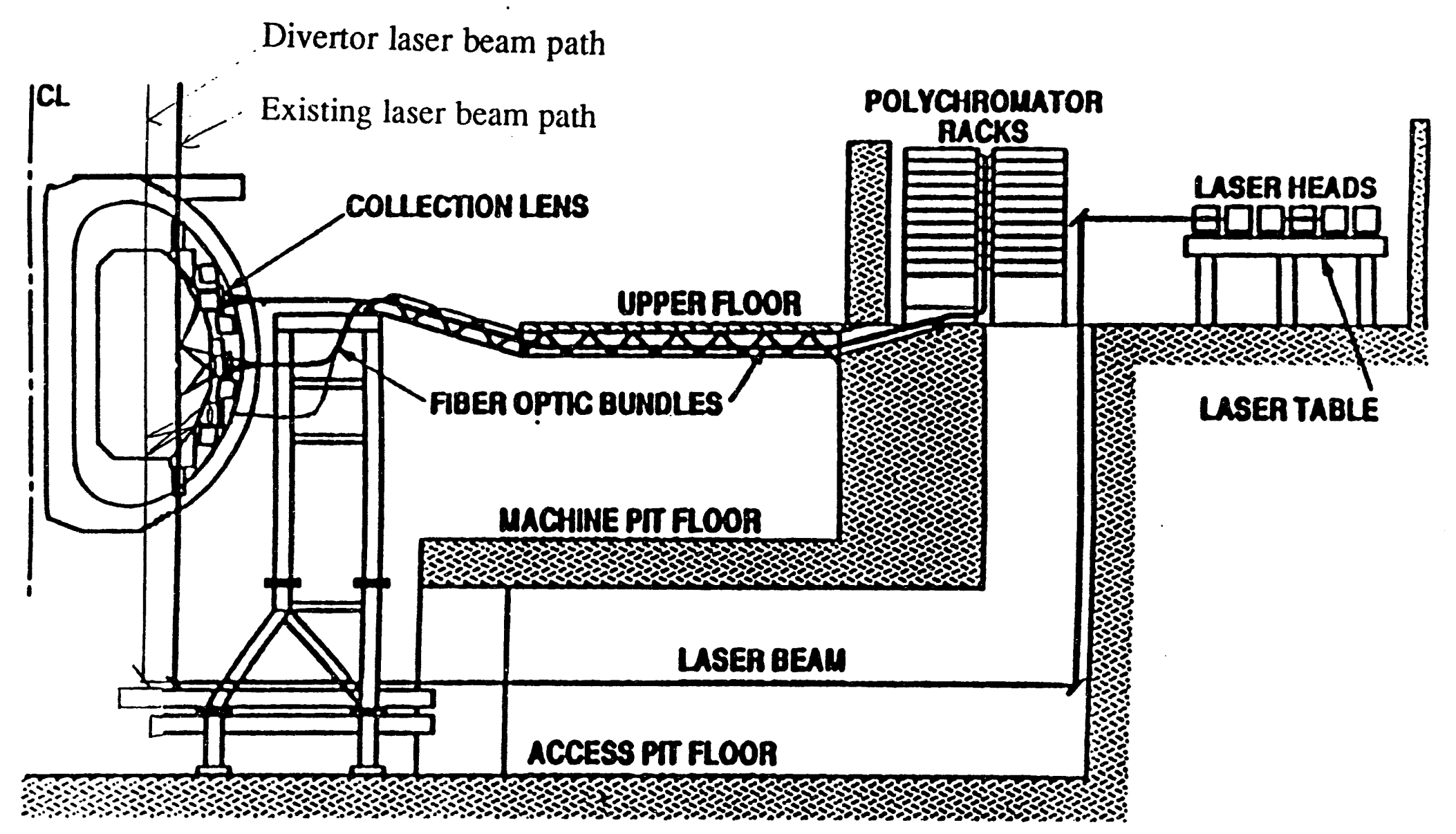

Figure 1. Overview of the Thomson scattering system showing the location of the existing laser beam path and the proposed divertor beam path. The collection lenses are mounted to the tower structure that holds the laser beam input optics. The two systems share the laser beam line and polychromator racks. 


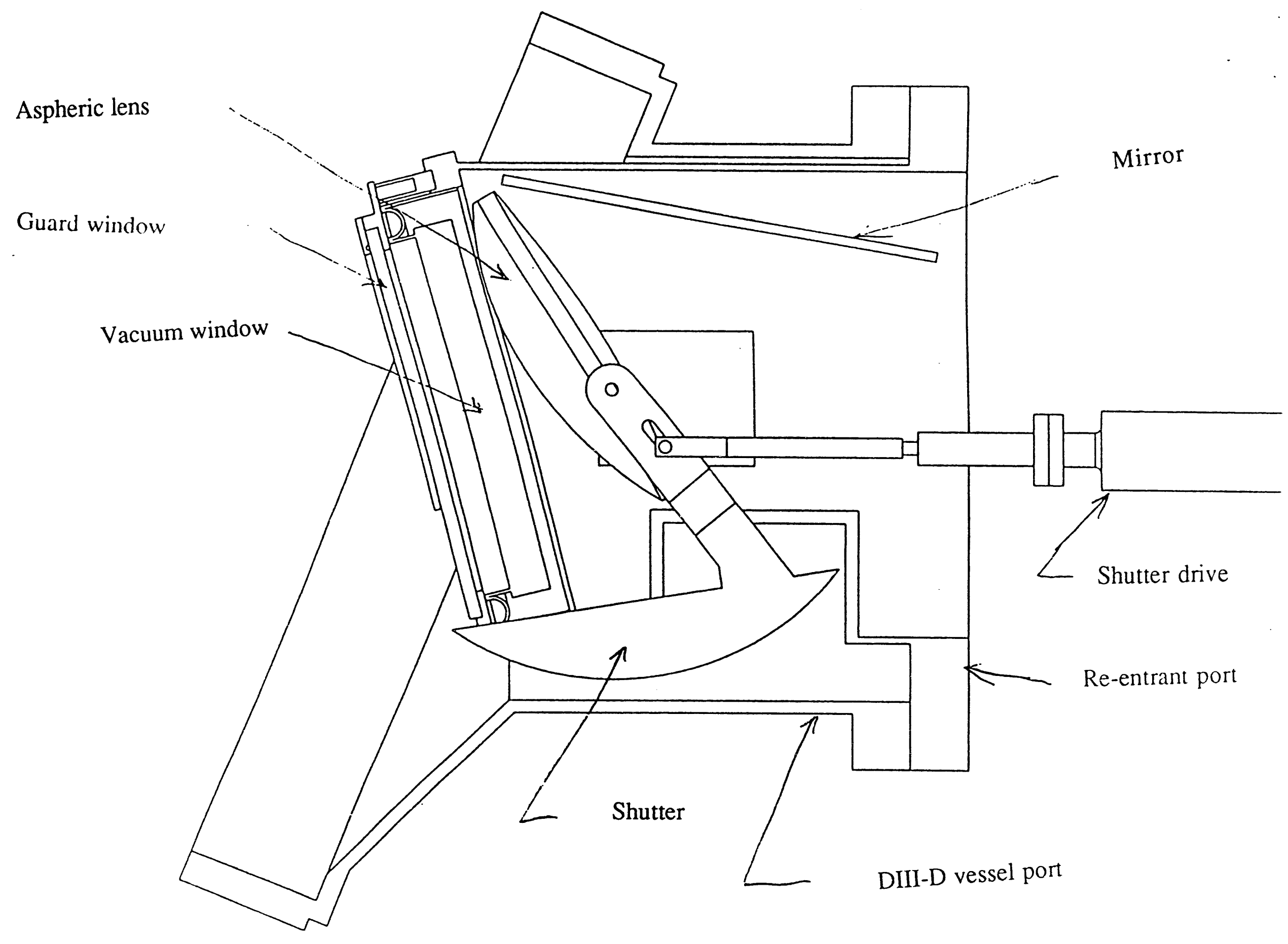

Figure 3. Detail of the collection lens assembly. 


\section{Fiber tranemiselon}

Detector quantum efflcioncy

Collectlon optlc efflciency

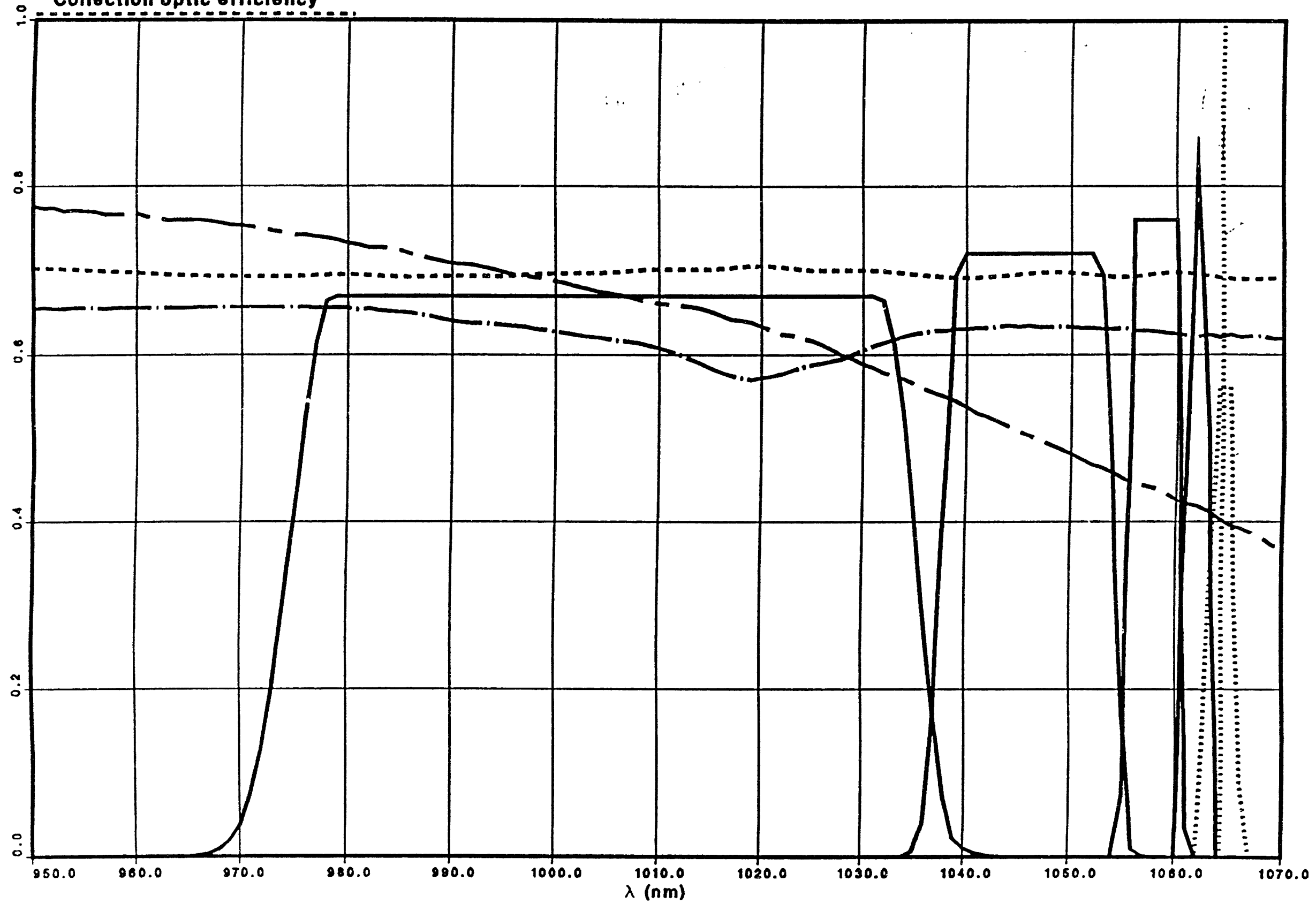

Figure 4. Proposed interference filter transmission functions for a 5 channel, low temperature polychromator. 


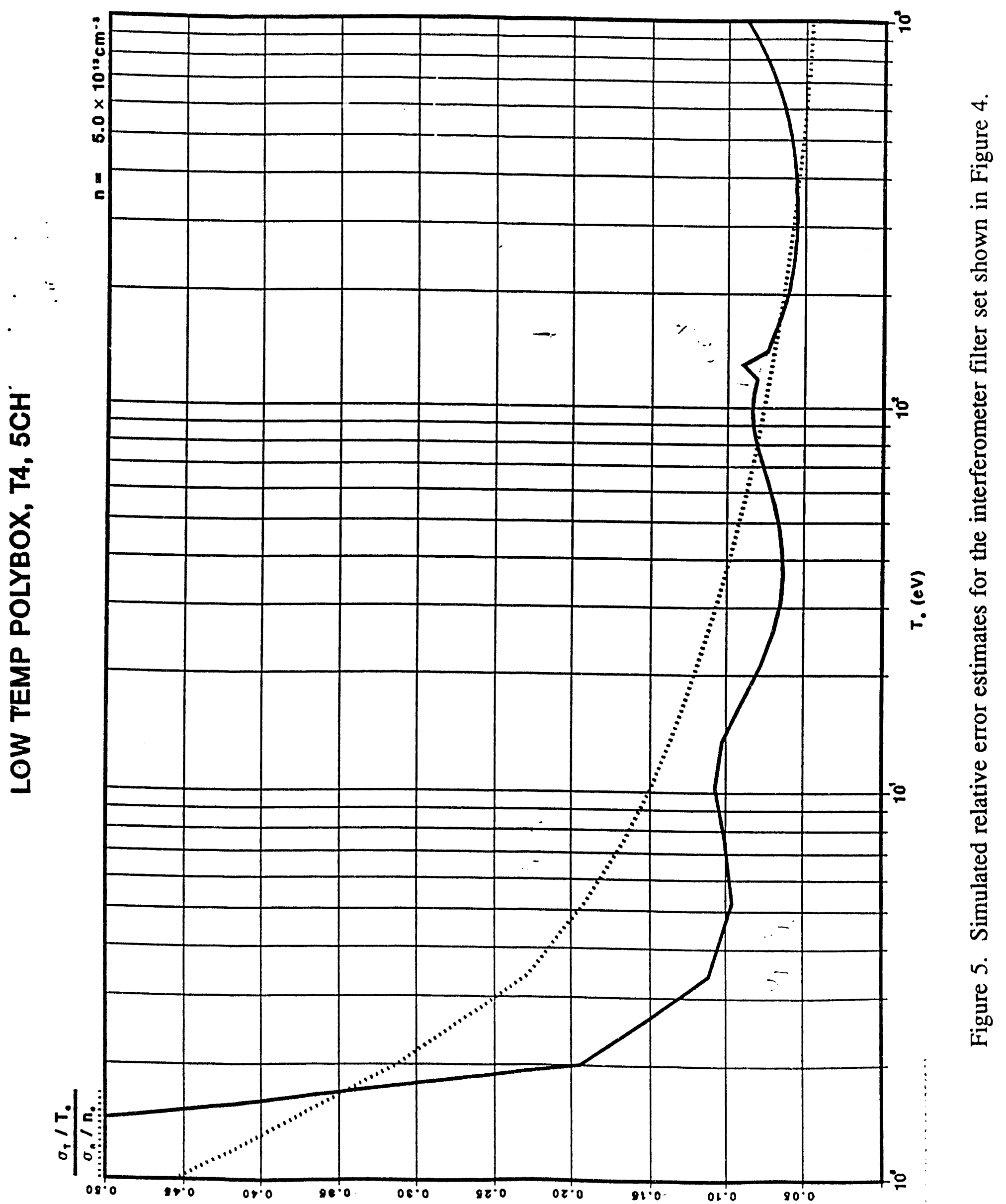



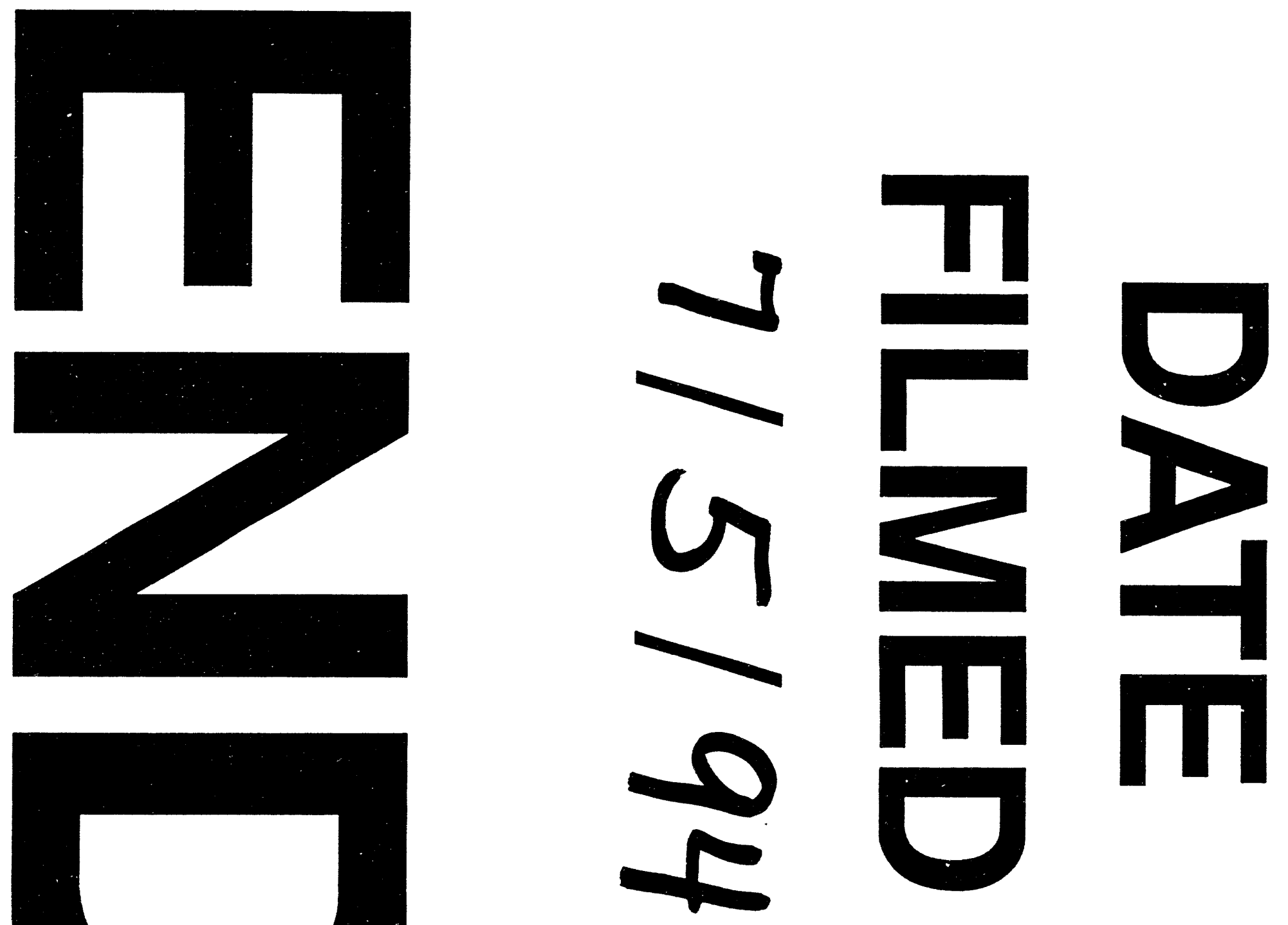
